\title{
Relações e condições de trabalho do assistente social na atualidade: a proletarização da profissão
}

\author{
Relationships and working conditions \\ of social workers today: the \\ proletarianization of the profession
}

\author{
Maria Angelina B. de Carvalho de A. Camargo ${ }^{a}$ \\ (D) https://orcid.org/0000-0003-1652-3992
}

\begin{abstract}
Resumo: Este artigo apresenta alguns dos percursos e dos "achados" investigativos de uma pesquisa* sobre as relações e as condições de trabalho de assistentes sociais no mercado de trabalho. Destaca as tendências em curso para o processamento da ação profissional através da tese da proletarização, que indica a precarização, a informalidade, a intensificação e a terceirização do trabalho - objetivada em níveis salariais baixíssimos, contratos temporários, subcontratações, espaços insalubres, sobrecargas, adoecimentos e humilhações.
\end{abstract}

Palavras-chave: Trabalho. Serviço Social. Mercado de Trabalho. Processamento da Ação Profissional. Proletarização.

\begin{abstract}
This article presents some of the investigative pathways and "findings" of a survey* on the relationships and working conditions of social workers in the labor market. Highlights the current trends for the processing of professional action through the proletarianization thesis, which indicates precariousness, informality, intensification and outsourcing of work aimed at very low salary levels, temporary contracts, subcontracting, unhealthy spaces, overloads, illnesses and humiliations.
\end{abstract}

Keywords: Work. Social Service. Marketplace of Work. Professional Action Processing. Proletarianization.

aUniversidade Federal do Espírito Santo (UFES), Departamento de Serviço Social, Vitória/ES, Brasil. *Tese de doutorado defendida em 2019, no Programa de Estudos Pós-Graduados em Serviço Social da Pontifícia Universidade Católica de São Paulo (PUC-SP), com o título Processamento e proletarização do trabalho do assistente social no acirramento da crise capitalista: estudo das condições e relações de trabalho na cidade de Teófilo Otoni-MG, sob orientação da Prof.a. Dra. Maria Carmelita Yazbek.

Recebido: 15/3/21 - Aprovado: 15/6/21 


\section{Introdução}

$\mathrm{E}$ ste artigo apresenta a tese da proletarização do trabalho do assistente social em tempos de capital fetiche e de crise estrutural profunda do capital, como mediação para explorar o processamento dessa especialização do trabalho no mercado. Os eixos de análise são as relações e as condições de trabalho em instituições empregadoras de natureza pública, privada e filantrópica de prestação de serviços, nas áreas da seguridade social, educação e sociojurídico. Para tanto, recorre-se à pesquisa bibliográfica e de campo para elucidar a proletarização como tendência contemporânea no Serviço Social, utilizando o eixo categorial precarização, informalidade, terceirização, intensificação. 0 artigo está organizado em três seções: 1. Capital fetiche e mundo do trabalho; 2. A tese da proletarização do trabalho do assistente social; 3. Manifestações da proletarização no trabalho profissional, além da conclusão.

\section{Capital fetiche e mundo do trabalho}

Marx já apontava, de modo precoce, a tendência sempre crescente de o capital fictício se manifestar na forma de propriedade dinheiro (D - D') e aprofundar a alienação da relação social de produção presidida pelo capital, na forma de capital portador de juros.

Na forma do capital portador de juros, portanto, esse fetiche automático está elaborado em sua pureza, valor que valoriza a si mesmo, dinheiro que gera dinheiro, e ele não traz nenhuma marca de seu nascimento. A relação social está consumada como relação de uma coisa, do dinheiro consigo mesmo. Em vez da transformação real do dinheiro em capital aqui se mostra apenas sua forma sem conteúdo. Como no caso da força de trabalho, o valor de uso do dinheiro torna-se aqui o de criar valor, valor maior que o contido nele mesmo [...] de tal modo que proporciona o juro não como capital funcionante, mas como capital em si, como capital monetário (Marx, 1986, p. 294). 
Essa tendência, na forma capital monetário portador de juros, distorce não apenas o juro como parte do lucro, como também faz parecer que juro é fruto do capital isoladamente ou "uma relação entre dois capitalistas e não entre capitalista e trabalhador" (Marx, 1986, p. 285). A finalidade é realizar a "troca de pele" para transluzir o capital como:

[...] coisa, mas como coisa capital. O dinheiro tem agora amor no corpo. Tão logo esteja emprestado ou também investido no processo de reprodução (desde que proporcione ao capitalista funcionante, como seu proprietário, juros separadamente do ganho empresarial), acresce-lhe juro, esteja dormindo ou acordado, em casa ou em viagem, de dia ou de noite. Realiza-se assim no capital monetário portador de juros [...] o desejo impiedoso do entesourador (Marx, 1986, p. 295).

Esse desejo impiedoso ao entesouramento reflete o processo de valorização do capital na figura autônoma que assume o juro na dinâmica capitalista atual. Para Marx (1986), o juro na figura particular do lucro nada mais é que mais-valia produzida pelo trabalhador, por meio não do trabalho concreto, mas do abstrato.

No capitalismo contemporâneo, Chesnais (2005, p. 35) assinala que o capital portador de juros apresenta-se no centro das relações sociais e econômicas, por meio da existência de grupos industriais e transnacionais que controlam a produção social. Esses grupos "têm por encargo organizar a produção de bens e serviços, captar o valor e organizar de maneira direta a dominação política e social do capital em face dos assalariados". É uma estrutura complexa, cujo papel das instituições financeiras bancárias e não bancárias é fundamental para impor a dominação burguesa do tempo presente, em que o:

[...] capital busca "fazer dinheiro" sem sair da esfera financeira sob a forma de juros de empréstimos, de dividendos e outros pagamentos recebidos a título de posse de ações e, enfim, de lucros nascidos de especulação bem-sucedida. Ele tem como terreno de ação os mercados financeiros integrados 
entre si no plano doméstico e interconectados internacionalmente. Suas operações repousam também sobre as cadeias complexas de créditos e de dívidas, especialmente entre bancos (Chesnais, 2005, p. 35).

Esse traço determinante é a forma como o capital portador de juros impõe uma era de especulação, como mecanismo à sua autovalorização. Para tanto, intensificar a exploração do trabalho, sua precarização em níveis mais degradáveis e desumanos, é essencial. Para isso, novas formas de controle, gerenciamento e organização do trabalho são vitais à produção global da produção capitalista, uma vez que o capital fictício não pode renunciar ao lastro produtivo.

Nesses termos, o mundo do trabalho torna-se território de reestruturação permanente e o florescimento das tecnologias da informação e comunicação (TICs) afigura-se em novo e central elemento (Antunes, 2018) no tempo presente. Por meio delas é possível reconfigurar os meios e a formas de realização do trabalho nas condições mais adequadas ao processo de valorização do capital.

Esses processos revelam o grau de desenvolvimento do capital como relação social de produção e o domínio da ciência, da tecnologia e do trabalho vivo, elevando a produtividade do trabalho, reduzindo o tempo de trabalho socialmente necessário, prologando o tempo destinado à valorização do capital e acentuando, no mundo do trabalho, os sofrimentos, os estranhamentos e as fetichizações das relações sociais de produção.

Dito isso, é importante considerarmos as novas condições e relações de assalariamento em curso no mundo do trabalho em suas tendências globais. Na atualidade, os processos de uberização e intermitência do trabalho têm se constituído em um traço determinante.

Vejamos o que Abílio (2020, p. 112) diz sobre a uberização:

A uberização do trabalho define uma tendência em curso que pode ser generalizável pelas relações de trabalho, que abarca diferentes setores da economia, tipos de ocupação, níveis de qualificação e rendimento, condições 
de trabalho, em âmbito global. Derivado do fenômeno social que tomou visibilidade com a entrada da empresa Uber no mercado, em realidade o termo uberização se refere a processos que não se restringem a essa empresa nem se iniciam com ela, e que culminam em uma nova forma de controle, gerenciamento e organização do trabalho.

Como parte desse processo, a intermitência se manifesta como "um dos elementos mais corrosivos da proteção do trabalho" (Antunes, 2020, p. 11), matizando a exploração da força de trabalho.

A uberização como tendência visa tornar as relações de trabalho mais individualizadas e invisibilizadas, de acordo com Abílio (2020). Esses fenômenos indicam o fim de uma era de gerenciamento da força de trabalho centrada no trabalho regulamentado, com vínculo formal e duradouro, para proliferar novas relações em que o núcleo é a desregulamentação da proteção, transformando o trabalho em ocasional e sem garantias. Destaca-se o papel ativo do Estado na concretização de tais finalidades, colocando as relações de compra e venda da força de trabalho em novo patamar de realização, haja vista as suas funções de legislador e regulador das relações sociais burguesas, agente vital na esfera da reprodução social.

A entrada e a permanência no mercado de trabalho são progressivamente modificadas, com formas mais precárias e destituídas de medidas protetivas, estando presentes a terceirização, a informalidade, a flexibilização nas relações de trabalho. Trata-se de uma tendência mundial que só acentua a degradação do trabalho.

O trabalho que caracteriza o nosso tempo é marcado:

[...] por bilhões de homens e mulheres dependentes de forma exclusiva do trabalho para sobreviver e encontrar, cada vez mais, situações instáveis, precárias, ou vivenciando diretamente o flagelo do desemprego. Isto é, ao mesmo tempo que se amplia o contingente de trabalhadores e trabalhadoras em escala global, há uma redução imensa dos empregos; aqueles que se mantêm empregados presenciam a corrosão dos seus direitos 
sociais e a erosão de suas conquistas históricas, consequência da lógica destrutiva do capital [...] recria, no mais distantes e longínquos espaços, novas modalidades de trabalho informal, intermitente, precarizado, "flexível", depauperando ainda mais os níveis de remuneração daqueles que se mantêm trabalhando (Antunes, 2018, p. 26).

O autor chama a atenção para a explosão do novo proletarizado de serviços e para os seus novos significados na cena atual, dadas a informatização da era financeira e a chamada industrialização dos serviços como novos espaços possíveis de geração de valor, sendo vitais "as TICs, presentes de modo cada vez mais amplo no mundo da produção material e imaterial e que tipificam também os serviços privatizados e mercadorizados" (Antunes, 2018, p. 35, grifos do original).

São processos que ocorrem no quadro histórico-social de aprofundamento da crise de superprodução de capital, cuja raiz reside na superprodução de mercadorias e na acumulação sem precedentes de capital fictício (Chesnais, 2013). O que revela que o capital encontra-se mais uma vez “[...] 'preso' por suas contradições, confrontando as barreiras que ele mesmo criou" (Chesnais, 2013, p. 26). A sua administração só é viável na "busca implacável por superlucros, processo impossível sem a exploração da força viva de trabalho" (Chesnais, 2013, p. 30). O que só agrava a situação dos trabalhadores diante das novas tendências de acumulação capitalista.

Nesse universo, expressões como zerados ou zero hour contract, trabalho por voucher, uberizados, pejotizados, intermitentes, flexíveis, autônomos, empreendedores, terceirizados e temporários integram o nosso cotidiano de maneira fluida, escamoteando as novas formas de efetivação do trabalho assalariado e seu disfarçamento - o não reconhecimento desses laços é crucial ao capital. Vê-se agora o porquê: a uberização e a intermitência apresentam-se como tendência que deve atingir todos os trabalhadores indistintamente.

A precarização é uma das formas históricas de objetivar a exploração do trabalho, não sendo desconhecida na trajetória de vida dos 
trabalhadores. Engels (2010), ao estudar as condições de vida e trabalho do proletariado industrial na Inglaterra do século XIX, já apontava esse fenômeno como inerente à dinâmica de acumulação, constatando os impactos da Revolução Industrial nas condições de trabalho, de vida e na subjetividade do proletariado, com o advento da máquina a vapor e das máquinas de processar o algodão. Demonstrou o empobrecimento acentuado de uma classe social em constituição e em desenvolvimento em níveis sempre volumosos: quanto mais trabalhava, mais riqueza gerava e mais desprovida dos meios fundamentais de vida ficava.

Na atualidade, a precarização se realiza por meio de novas mediações que particularizam os processos de exploração do trabalho, dada pela ampla reestruturação produtiva que introduz a terceirização, a informalidade, a flexibilidade e a intensificação, expondo a destrutividade motriz do capital sob a força humana de trabalho, sendo orquestrada de forma impiedosa pelo capital portador de juros.

Sendo assim, é necessário considerarmos o papel estratégico das TICs e a sua expansão sem limites na atualização "entre os distintos mecanismos de acumulação criados pelo capitalismo financeiro de nosso tempo" (Antunes, 2020, p. 13), proporcionando que o tempo da produção e o de trabalho sejam prolongados, dinamizando a composição orgânica do capital. Um mosaico que aprofunda o desemprego, os adoecimentos, os assédios, as humilhações, as condições sub-humanas de reprodução no mercado, cujo registro é o maior empobrecimento dos trabalhadores.

\section{A tese da proletarização do trabalho do assistente social}

O Serviço Social se configura na divisão social do trabalho como uma especialização do trabalho coletivo, pertencente, nos termos de Antunes (2018), ao "mundo capitalista dos serviços" ${ }^{\text {como trabalho }}$

1 Os serviços e a natureza desse trabalho são polêmicos, remetem ao debate do trabalho produtivo e improdutivo em Marx, o que não é consenso inclusive na própria tradição marxista. Para Rubin 
improdutivo. Não está em questão aqui se a profissão é geradora de valor ou não, mas a "identidade do trabalho do assistente social, enquanto trabalho abstrato, com o trabalho social médio: como parte alíquota do trabalho total socialmente produzido. As implicações do trabalho do assistente social no circuito do valor [...] na sociedade do capital fetiche" (Iamamoto, 2008, p. 418, grifo do original). Uma especialização que vem sofrendo as injunções em curso, vivenciando assim com o conjunto da classe trabalhadora a precarização do trabalho nas distintas instituições empregadoras, manifestadas em graus e níveis diferenciados. 0 que pode ser demarcado por indicadores diversos, como salário, jornada de trabalho, quantidade de vínculos de trabalho, formas de contratação e infraestrutura de realização do trabalho (equipamentos, instalações físicas, etc.).

O mercado de trabalho para os assistentes sociais vem sendo modificado não apenas em relação às demandas e às requisições profissionais; está revestido de uma intensa precarização das condições e relações de trabalho, e na constituição de novas modalidades de contratação e gerenciamento dessa força de trabalho.

A hipótese é de presenciarmos a proletarização do trabalho do assistente social em dimensões até então desconhecidas do universo profissional, demarcada por uma intensa pauperização das condições de vida e de trabalho. $O$ que pode ser, inicialmente, visualizado pela condição salarial, mas não só, também pelo processo sugestivo a partir da pesquisa realizada no mercado de trabalho dos assistentes sociais, entre 2018 e 2019, em um município de médio porte, no nordeste mineiro. $\mathrm{Na}$

\footnotetext{
(1987, p. 277), o debate do trabalho produtivo "está cheio de desacordos e confusão conceitual [...] tanto entre marxistas como entre estes e seus adversários”. Convém destacar que “[...] a distinção entre trabalho produtivo e improdutivo não diz respeito ao conteúdo, ao caráter do trabalho útil ou de seus produtos, sendo indiferente à sua natureza material e imaterial [...]. No âmbito dos serviços, a produção capitalista era reduzida a um grau mínimo na época de Marx, apresentando-se, de modo muito limitado, quando comparada com a produção material, algo distinto do que ocorre na atualidade com o crescimento dos serviços sob a órbita do capital" (Iamamoto, 2008, p. 87).
} 
ocasião, o mercado era constituído por 103 profissionais, ${ }^{2}$ consistindo em 44 espaços ocupacionais, por meio de 25 instituições empregadoras. Desses, 77\% estavam em instituições públicas, nos níveis municipal, estadual e federal. As instituições privadas registravam a presença de $7,6 \%$ e as instituições sem fins lucrativos $15,4 \%$.

Identificamos que além de os profissionais estarem subordinados a níveis salariais baixíssimos, quase equivalentes a um salário mínimo, marcavam presença os contratos temporários, as subcontratações (realizadas pelo mesmo empregador), jornadas duplas e intensas, assim como a tendência à terceirização do trabalho nas UPAs (Unidades de Pronto-Atendimento), ao home office no INSS ou ao trabalho por metas, dentre outros. Processos que se efetivam em instalações físicas extremante precárias, insalubres, despidas de condições mínimas de dignidade humana para a realização do trabalho (e até a ausência de espaços físicos para realização dele), sem telefone, dentre outros insumos e equipamentos.

Sobre essas tendências, como home office e o impacto das TICs, os profissionais do INSS destacam:

O INSS está lançando esse projeto novo, ainda não começamos, mas não sabemos como isso vai ocorrer aqui dentro (Previdência Social).

Quando você adere, você perde vale-transporte, vale-alimentação e vai gastar a sua energia, a sua internet. Para comportar o sistema do INSS você tem que arcar com uma internet boa, um computador, a manutenção do computador. Infelizmente, vejo colegas achando maravilhoso (Previdência Social).

A expressão proletarização é empregada aqui em sentido amplo, para caracterizar as tendências contemporâneas no mundo no trabalho de acentuada precarização e de pauperização das relações de trabalho.

2 A metodologia da pesquisa foi de natureza quantitativa e qualitativa, utilizando dois instrumentos de coleta de dados, o questionário e a entrevista com roteiro semiestruturado. Na pesquisa quantitativa, participaram 47 profissionais, e, a partir desses dados, 18 foram selecionados para a entrevista. 
A palavra proletarização vem do latim proles (raça, linhagem, família, prole, filho, posteridade), dá origem à expressão proletariado (latim proletarǐus, ̌i, o que equivale apenas por sua prole). Diz respeito a um conjunto de descendentes, sempre numerosos, que vivem em condições precárias de vida, com poucas condições de sobrevivência, submetidos a relações de trabalho degradáveis. Sobre essa questão, diz Antunes (2020, p. 92):

Sabemos que Marx e Engels consideravam classe trabalhadora e proletariado como sinônimos. E que, na Europa de meados do século XIX, os trabalhadores assalariados que inspiraram a reflexão de ambos ganhavam expressão corpórea no proletariado industrial, o que possibilitava a dominação comum e mesmo indiferenciada entre classe trabalhadora e proletariado.

O autor revela a explosão do novo proletariado de serviços e a forma como esses trabalhadores estão submetidos à informalidade, à flexibilidade, à terceirização como tendência geral e que não poupa nenhum trabalhador, ou se a atividade é mais intelectualizada ou manual, se é produtiva ou improdutiva, se é trabalho material ou imaterial. Estamos diante de uma monumental forma de exploração e consumo da força de trabalho que conduz todos os trabalhadores para uma precarização estrutural. São modificações que reconfiguram a divisão do trabalho e nos colocam diante de uma nova morfologia do trabalho.

\section{Manifestações da proletarização no trabalho profissional}

O assistente social trabalha sob o controle direto do empregador, a quem pertence o uso da sua força de trabalho por um tempo determinado. No percurso, identificou-se que a grande parte dos trabalhadores está inserida em uma jornada de trabalho de 30 a 40 horas, mas também por meio das subcontratações chegam a 55. Para Dal Rosso (2006, p. 33), a jornada de trabalho no mundo atual se manifesta por meio de dois 
elementos: duração e intensidade," "a duração da jornada de trabalho e sobre seu grau de intensidade resulta que nos dias de hoje convergem tendências que acumulam repercussões sobre a exploração do trabalho", pois "intensificação do trabalho e alongamento da jornada são condições que podem conviver juntas enquanto essa união não colocar em risco a vida do trabalhador por excesso de envolvimento com o trabalho".

Sou concursada para o cargo, mas também tenho com a Prefeitura um contrato temporário. Por meio do meu salário faz-se o cálculo, a partir de quanto ganho por dia e por hora e recebo proporcionalmente as horas trabalhadas no novo contrato. É uma subcontratação dentro do meu contrato, onde eu tenho que ficar submetida aos interesses daqui e da instituição que estou cedida (Assistência Social).

$\mathrm{Na}$ assistência social, esse profissional exerce a jornada diária de dez horas, e semanal de 50 horas, além de indicar perversamente o valor da força de trabalho e a sua desvalorização monetária no mercado. Essa tendência se faz presente na saúde, sob os moldes da contratação para o exercício de uma dupla função, como técnico e gestor do serviço, expressando a multifuncionalidade da força de trabalho, e sem linhas divisórias de quando começa o trabalho de técnico e o de coordenação. O profissional é contratado para uma carga horária diária de oito horas e deve administrá-la entre as duas funções.

São processos de precarização que encolhem o tempo livre e se manifestam nos distintos espaços de trabalho, conforme se registra a seguir:

3 De acordo com Dal Rosso (2008), intensidade e produtividade não são sinônimas. O conceito de produtividade nasce nos marcos da economia como forma de considerar o trabalho mais produtivo, nos "resultados que decorrem de avanços efetuados tão somente nos meios materiais com os quais o trabalho é realizado. Chamamos esse aumento de resultado de produtividade" (Dal Rosso, 2008, p. 25). A intensidade está relacionada com o ato de trabalhar e ao grau de dispêndio de força e energia acionadas pelo trabalhador no trabalho concreto, efetivada na dimensão do trabalho abstrato. A forma como se efetiva a intensidade "é transferida com o ato de compra e venda da força de trabalho das mãos do vendedor para as mãos do comprador" (Dal Rosso, 2008, p. 24). 
A demanda que apresenta pra gente é muito complexa e complicada, e ela demanda mais tempo do que o nosso horário de trabalho. Às vezes a gente passa horas a mais aqui, de trabalho, meu horário é até às 13h00, às vezes saio às 15h00. Eu não posso apenas dizer para o usuário: pega isso aqui e pronto (Assistência Social).

São de 15 a 20 atendimentos só na parte da manhã. Não dá para determinar o horário de cada atendimento, porque cada um tem uma demanda diferente, e quando o usuário chega para você ele quer ser ouvido. Então você perde um certo tempo para essa escuta, tanto que os últimos atendimentos ficam prejudicados, na questão de ir mais a fundo. Eu também já estou cansada, já não consigo mais raciocinar - nem eu, nem a minha colega. A gente aproveita esse momento do atendimento, porque observa que essa continuidade de acompanhamento, que é o trabalho do CRAS, fica dificultoso, visto que ficamos imersas nessa demanda. Teria que ter outra equipe com mais assistentes sociais e psicólogos para dar conta, teria que dobrar para acompanhar o usuário na forma que pede a política. O horário é até às 12h00, mas em dias de atendimento não tem condições, chegamos a sair às 13h00. Não conseguimos parar para tomar um café ou sequer ir ao banheiro; às vezes quando uma levanta para tomar uma água já pega para outra por conta do tempo, por conta do sufoco (Assistência Social).

Os relatos anteriores são de profissionais submetidos a contratos temporários de 12 meses e jornada diária de seis horas. Interessante notar que, no relato a seguir, uma delas destaca fazer horas a mais, como forma de sensibilizar a instituição para a renovação do seu contrato.

Às vezes chego pensando assim: será que se eu fizer para além eles podem renovar o meu contrato? A colega diz: "Fulana, isso não é competência sua, passa à frente". Mas fico com receio de ter alguma reclamação e ter problemas com o contrato, futuramente. Já aconteceu elogios por parte da instituição e dos usuários (Assistência Social).

A maior parte dos Assistentes Sociais são contratados e é muito difícil. Todo dia primeiro de cada ano é um perigo, não sabemos se o contrato será renovado. A incerteza e a insegurança são grandes. Chega no dia primeiro 
de cada ano não sabemos se vamos trabalhar, principalmente em mudança de governo (Assistência Social).

Os depoimentos revelam o aumento da precarização e do nível de degradação do trabalho e o indicador da erosão de empregos estáveis. Combinam-se elementos, para usar uma expressão de Antunes (2018), de uma fenomenologia da superexploração do trabalho, que atesta uma tendência quase homogênea de contratação da força de trabalho para todos os ramos da produção social, tornando as relações de trabalho mais flexíveis, desregulamentadas e adaptadas aos desdobramentos da reestruturação produtiva.

O profissional define o que seria para ele a precarização ou suas manifestações:

A questão salarial é uma expressão da precarização, infelizmente a gente vê. Eu não estou na Assistência Social, o salário da assistência há 12 anos é o mesmo no município, $R \$ 1.080,00$. Há 12 anos eu fazia estágio e o salário era esse. Eu faço dez anos de formada agora, eu fiz dois anos de estágio e a questão salarial não mudou. Também tem o fato de a gente dividir uma sala com mais de um técnico, por exemplo, é uma precarização. São "N" situações, igual à questão de telefone, que não temos (Saúde).

Chegamos nos locais para realizarmos as inspeções técnicas via o roteiro de atuação da Coordenadoria, e é visível o sucateamento da política pública, além das péssimas condições de trabalho e de salário dos profissionais. Passa pela questão salarial, pela rotatividade de trabalho. Você vai lá hoje tem uma equipe, se no município do lado estiver ofertando um salário melhor, o profissional muda para o outro município. Isso ocorre muito. A gente chega numa entidade e fala: "você está aqui?" Aí passa três meses e vamos fazer outras inspeções, ele já está em outro município, por questão meramente salarial (Sociojurídico).

Para o profissional, o controle sobre o trabalho configura-se como uma forma de intensificar a jornada de trabalho e se manifesta de modo diferente em cada espaço sócio-ocupacional: 
A gente tem a meta da Coordenadoria. Temos um planejamento, então dentro desse planejamento tentamos atingir o que é planejado. Outra meta a ser cumprida se refere ao cumprimento dos prazos constantes nos despachos do Promotor de Justiça. Entretanto, os prazos são razoáveis e flexíveis, podendo ser negociados diante de uma situação que justifique a dilatação do prazo (Sociojurídico).

No Nasf [Núcleo de Apoio à Saúde da Família], nós temos meta a cumprir. Cada assistente social, com carga horária de 30 horas de trabalho, tem que realizar, no mês, no mínimo, 38 atendimentos individuais. Na verdade, esses 38 atendimentos referem-se à quantidade que cada técnico da equipe deve realizar [o cálculo é o seguinte: são sete técnicos, logo a equipe deve realizar 266 atendimentos]. Aí eu tenho que fazer no mês no mínimo 38 atendimentos. Para a instituição interessa apenas a quantidade dos atendimentos para lançar no sistema SUSfácil, não se olha qual a demanda que foi atendida, se foi resolvido. A qualidade eles não olham, eles querem saber do quantitativo no sistema (Saúde).

A equipe tem que cumprir mensalmente 20 atendimentos às famílias. Dividimos esse quantitativo pelos seis técnicos para que possamos cumprir a meta mensal. Precisamos lançar numa planilha que já é do sistema (Sociojurídico).

No INSS, esse processo se revela mais acentuado com impacto no salário. Os profissionais relatam que a instituição estabelece uma meta individual (qualitativa) e uma coletiva que devem ser simultaneamente cumpridas para que o servidor possa elevar o salário mensal por meio de gratificações. "Atendendo à demanda, a gente vai ter o salário, se a gente não atender aí ocorre uma redução no salário" (Previdência Social).

O profissional refere-se à meta qualitativa, que corresponde a $20 \%$ sobre o salário-base, conforme explicação a seguir:

É porque o nosso salário-base é de 800 e poucos reais, o resto é gratificação. $O$ impacto é sobre a gratificação e não no salário-base. O nosso maior salário vem da gratificação. Se tiver que escolher entre o salário-base e a gratificação, é melhor ficar com a gratificação. Já é uma estratégia da instituição, porque o salário-base é mantido, não é alterado (Previdência Social). 
As gratificações representam um impacto no salário de mais de 70\%. A composição se dá da seguinte forma:

A meta coletiva, que não é do Serviço Social, é dos servidores do INSS, que é $80 \%$. Essa meta coletiva bate, nisso aqui, comprimir os índices, e aí o que acontece? Vou te dar um exemplo, aí é da gerência inteira, das 13 agências: suponhamos que as 12 agências estão cumprindo a meta e Teófilo Otoni não. Só que Teófilo Otoni, por ser a maior agência, ela derruba a meta de todo mundo, e impacta no número de todas as gerências. Assim como o não cumprimento da meta de uma agência menor pode impactar no resultado final. O que isso faz? Leva muitos trabalhadores a pensarem: "bom, eu estou fazendo a minha parte, mas eu tenho que cobrar de outro colega que não está fazendo a parte dele". É uma lógica perversa, de fiscalização do trabalho do outro. Um servidor fiscaliza o outro. Isso ai é $80 \%$ da meta. Agora, tem os $20 \%$ que é individual, que é a sua avaliação individual. Que a chefia imediata realiza, no caso, o gerente da agência (Previdência Social).

A avaliação de $20 \%$ que compõe parte da meta é uma avaliação qualitativa, diferente da coletiva, que é quantitativa e leva em consideração se o servidor está suscetível a mudanças, se é flexível às normas da instituição, por exemplo. Vejamos o que diz o profissional:

Se você perder um ponto não tem impacto direto no seu salário, como tem na outra. A quantitativa é a meta terrivel, que obriga um colega a fiscalizar o trabalho do outro [...] quando eu falei que tem um tempo médio de espera, que envolve os 45 dias, você pega uma senha, você está agendado para as 8 horas da manhã e 9 horas eu não te atendi. Eles medem, aferem tudo isso, o tempo de espera do usuário. Aí, nossa! Mas o fulano tá demorando chamar. Por exemplo, a gente tem para a avaliação social uma hora, só que tem casos que eu vou gastar 45 minutos, tem casos que eu vou gastar uma hora e 15 minutos, porque eu vou fazer encaminhamento, eu vou precisar fazer a socialização da informação, que ocorre também no atendimento individual. Você orienta para o direito a outro benefício de alguém da família que está acompanhando o usuário, ou uma série de questões, então isso é tão difícil (Previdência Social). 
Acrescenta que a instituição não considera:

Se você está com a agenda cheia, atendendo, atendendo, se você bloqueou a agenda para fazer esse planejamento, isso não é valorizado. Para a instituição, o profissional não está fazendo nada. Fora as informações que o profissional realiza por telefone para os profissionais - isso não conta; por e-mail, você manda e-mail, você responde. Isso não é mensurado (Previdência Social).

Importante enfatizar que, para Antunes (2018), a gestão por metas é um desdobramento da reestruturação produtiva, disseminada, sobretudo, a partir dos anos 1980, no auge do fortalecimento da lógica de racionalização da economia global, baseada na crescente mensuração por resultados, já delineada pelas configurações que se colocam no mundo capitalista a partir dos anos 1970.

A condição salarial dos profissionais é extremamente precária, relevando a desvalorização monetária dessa força especializada no mercado. Aferimos que $70 \%$ recebem renda mensal bruta quase equivalente ao salário mínimo (com base no ano de 2019), na sua grande maioria, são os trabalhadores da assistência social com o menor salário. Na saúde, os concursados aproximam-se de três salários. Nos hospitais filantrópicos, o pagamento chega a ser superior a dois salários mínimos. Nos hospitais particulares, pode chegar à faixa de três a quatro salários mínimos. Na educação, encontramos os salários mais elevados, no caso do trabalho docente, delineado pela titulação, variando de cinco a 13 salários mínimos, embora, na educação privada, o técnico da assistência estudantil esteja no patamar superior a dois salários mínimos. Os maiores salários, fora a área da educação, estão no sociojurídico, superiores a nove salários mínimos, no entanto, para os profissionais que atuam na segurança pública, esse valor cai para três. Na previdência social, a remuneração é equivalente à dos técnicos do Ministério Público, no entanto, atingir essas cifras condiciona-se ao cumprimento de metas, conforme exposto anteriormente. 
Nesse universo de trabalho, também estão presentes a escassez de recursos e a precariedade das instalações físicas. O espaço físico das instituições que abrigam o profissional se estrutura na esteira da precariedade das políticas sociais. Identificamos espaços improvisados, com pouca ventilação e iluminação - além da inadequação acústica, que compromete o sigilo no ato do atendimento e, também, a ausência desse espaço:

Hoje perdemos essa sala, e hoje ficamos peregrinando pelos PSF. Para os atendimentos em cada PSF, às vezes o enfermeiro dá licença da sala dele e nos empresta o espaço, ou usamos a sala do atendimento médico, caso não haja atendimento naquele dia, [...] então tem aquelas comunidades que têm uma igreja, ou uma escola, ou uma quadra, que é emprestada para o município para fazer as atividades do PSF. [...] só que esses locais onde a gente faz as atividades não têm a estrutura física adequada. Numa igreja evangélica, por exemplo, onde fazemos algum grupo, se tiver um velório nesse local, você chega e não pode desenvolver a atividade programada (Saúde).

Ainda sobre as instalações físicas, os profissionais relatam a precária estrutura de transporte para a realização das visitas domiciliares e institucionais. No caso do Cras e do Cress, os profissionais relatam que dispõem de transportes para realizar as visitas domiciliares apenas uma vez por semana, isto é, quando a instituição consegue garantir. Essa infraestrutura necessária à realização do trabalho, quando não acessada pelo profissional ou acessada em condições limitadas, contribui para a acumulação de tarefas, dado o fluxo de atendimento diário na instituição.

Dentre todos os processos que interpelam o Serviço Social no mercado de trabalho, cabem destacar, também, os impactos dessas condições na saúde do trabalhador. Constatou-se que os reflexos são os adoecimentos, manifestados em doenças como a depressão e a fribromialgia, conforme depoimentos a seguir:

Hoje estou em tratamento, mas hoje vejo que isso é reflexo desse acúmulo de trabalho, como a fribromialgia - doença que piora quando você tem 
certo grau de estresse. Eu estou me sentido um pouco nessa linha, porque eu já estou um pouco cansada mesmo. No contato com a equipe, outras colegas reclamam dessas questões também com o peso da carga de trabalho (Assistência Social).

São 30 horas semanais conforme previsto em lei, no entanto, a questão aqui é que geralmente ofluxo de atendimento às vezes é muito grande e eu tento controlar esse atendimento, que é de acordo com o que eu dou conta de atender. Sobrecarga, hoje eu não falo que eu tenho, porque hoje eu já estou conseguindo lidar melhor com essa carga horária de atendimento, mas eu não sei nem se leva em conta isso, mas eu cheguei a adoecer no ano passado. Eu cheguei a ter o diagnóstico de síndrome de Burnout e princípio de depressão por conta da sobrecarga (Educação).

Os depoimentos anteriores colaboram para a assertiva de Antunes (2018, p. 142) de que "a pressão por uma capacidade imediata de resposta dos trabalhadores às demandas do mercado [...] tem convertido, paulatinamente, o ambiente de trabalho em espaço de adoecimento", estando presente "a progressiva diminuição ou ausência do mínimo de controle dos trabalhadores sobre o processo de trabalho. Ocasionando adoecimentos como problemas osteoarticulares, distúrbios gastrintestinais, cardiovasculares, de saúde mental e acidentes de trabalho" (Antunes, 2018, p. 143).

São todos esses processos em curso e presentes no mercado do assistente social que sugerem a tese da proletarização do trabalho profissional. O que, na verdade, é uma tendência à reprodução do trabalho na sociedade de classes, revelando um dos retratos do mundo do trabalho em suas novas tendências e incidências no Serviço Social, mas também sob o conjunto da classe trabalhadora.

\section{Conclusão}

A análise das condições e das relações de trabalho em que estão inseridos os assistentes sociais na atualidade é determinada pelas novas exigências do capital. Assim, a precarização imbrica-se na informalidade, 
na intensificação, na terceirização e na proletarização do trabalho. As condições e as relações de trabalho vivenciadas pelos profissionais articulam um conjunto de mediações que interferem no processamento da ação profissional, situando-se na moldura contraditória que é a sociedade burguesa em sua totalidade concreta.

A precarização no capitalismo contemporâneo viceja a proletarização generalizada de todos os trabalhadores indistintamente, acentuando a pauperização, a expropriação, avultando as fileiras do exército industrial de reserva e impondo a disponibilidade perpétua para o labor (Antunes, 2018). Ao passo que, na realidade concreta, identificamos inúmeros trabalhadores desempregados, subempregados, intermitentes, uberizados, terceirizados etc. Processos que expressam a redefinição das condições de vida e trabalho na atualidade.

\section{Referências}

ABÍLIO, Ludmila Costhek. Uberização: informalização e o trabalhador just-in-time. Estudos Avançados, São Paulo, v. 34, n. 98, jan./abr. 2020. Disponível em https://www. scielo.br/scielo.php?script=sci_arttext\&pid=S0103-40142020000100111. Acesso em: 10 maio 2020.

ANTUNES, Ricardo. O privilégio da servidão: o novo proletariado de serviços. 2. ed. rev. e ampl. São Paulo: Boitempo, 2018.

ANTUNES, Ricardo. Trabalho intermitente e uberização do trabalho no limiar da indústria 4.0. In: ANTUNES, Ricardo (org.). Uberização, trabalho digital e indústria 4.0. São Paulo: Boitempo, 2020.

CHESNAIS, François. O capital portador de juros: acumulação, internacionalização, efeitos econômicos e políticos. In: CHESNAIS, François (org.). A finança mundializada: raízes e políticas, configuração, consequências. São Paulo: Boitempo, 2005.

CHESNAIS, François. As raízes da crise econômica mundial. Em Pauta, Rio de Janeiro, n. 31, p. 21-37, 2013.

DAL ROSSO, Sadi. Jornada de trabalho: duração e intensidade. Ciência e Cultura, v. 58, n. ${ }^{\circ}$ 4. São Paulo, out./dez. 2006. Disponível: http://cienciaecultura.bvs.br/pdf/cic/v58n4/ a16v58n4.pdf. Acesso em: 10 maio 2020. 
DAL ROSSO, Sadi. Mais trabalho!: a intensificação do labor na sociedade contemporânea. São Paulo: Boitempo, 2008.

ENGELS, Friedrich. A situação da classe trabalhadora na Inglaterra. São Paulo: Boitempo, 2010.

IAMAMOTO, Marilda. Serviço Social em tempo de capital fetiche: capital financeiro, trabalho e questão social. 2. ed. São Paulo: Cortez, 2008.

MARX, Karl. O capital: crítica da economia política. São Paulo: Nova Cultural, 1986. Livro terceiro, v. IV.

RUBIN, Isaak Illich. A teoria do valor. São Paulo: Polis, 1987.

\section{Sobre a autora}

Maria Angelina B. De Carvalho de A. Camargo - Mestre e Doutora em Serviço Social pela PUC-SP. Professora adjunta do Departamento de Serviço Social. Pesquisadora no Núcleo de Estudos do Trabalho (NET) do Departamento de Serviço Social da UFES.

E-mail: mariaangelinacarvalho@uol.com.br 